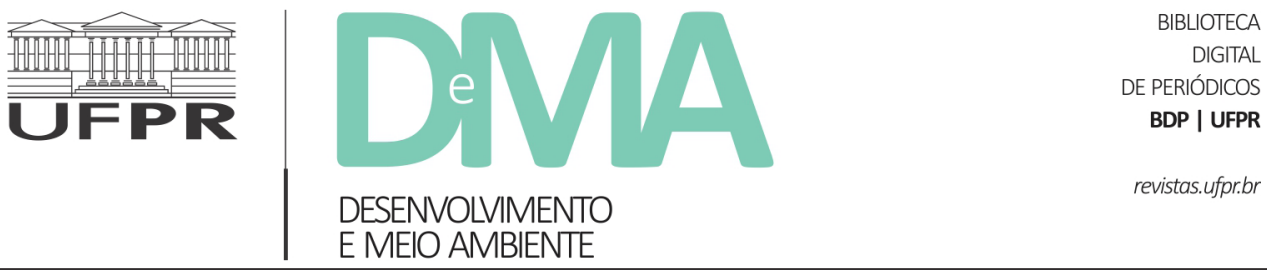

\title{
A gestão da pesquisa científica no Parque Estadual da Ilha do Cardoso
}

\section{The management of scientific research in the State Park of Ilha do Cardoso}

\author{
Emanuelle SPIRONELLO ${ }^{1 *}$, Juliana Costa COELHO ${ }^{2}$, Marcos Buhrer CAMPOLIM ${ }^{3}$, Lucas Citele CANDIDO ${ }^{4}$ \\ ${ }^{1}$ Escola Superior de Agricultura Luiz de Queiroz (ESALQ), Universidade de São Paulo (USP), Piracicaba, SP, Brasil. \\ ${ }^{2}$ Fundação Florestal, Secretaria de Infraestrutura e Meio Ambiente do Estado de São Paulo, São Paulo, SP, Brasil. \\ ${ }^{3}$ Instituto Florestal, Secretaria de Infraestrutura e Meio Ambiente do Estado de São Paulo, São Paulo, SP, Brasil. \\ ${ }^{4}$ Instituto Oceanográfico, Universidade de São Paulo (USP), São Paulo, SP, Brasil. \\ *E-mail de contato: manu.spironello@gmail.com
}

Artigo recebido em 1 de julho de 2019, versão final aceita em 27 de junho de 2020, publicado em 14 de dezembro de 2020.

RESUMO: $\quad$ A pesquisa científica é importante para a gestão das Unidades de Conservação - UCs, pois subsidia o planejamento de ações para conservação e manejo da natureza. Entretanto, os resultados das pesquisas dificilmente são utilizados no dia a dia da gestão. Este trabalho visa a propor estratégias para contribuir com o uso do conhecimento científico pelo Parque Estadual da Ilha do Cardoso, identificando o cenário atual do gerenciamento da pesquisa e as expectativas e dificuldades referentes ao acesso e comunicação do conhecimento científico. Para isto, foram realizadas entrevistas semiestruturadas com pesquisadores, funcionários e comunitários da UC. O resultado permitiu a identificação de problemas relacionados à desatualização do banco de pesquisas, à deficiência no apoio logístico aos pesquisadores e no monitoramento de pesquisas por parte da UC; além dos formatos inadequados dos produtos das pesquisas para a efetiva utilização pela gestão; e o receio da comunidade tradicional com resultados de estudos que comprometam sua permanência no Parque. A solução destas problemáticas está no entendimento de que a pesquisa científica é parte fundamental e integrante da rotina das UCs, devendo a gestão estabelecer iniciativas e estratégias para melhorar o cenário administrativo e aproximar a comunidade das ações de pesquisa; assim como o pesquisador assumir a responsabilidade diante do processo de difusão, popularização e democratização do conhecimento científico, tendo em vista a realidade do local e a missão de contribuir para a resolução de problemas e abertura de novas possibilidades.

Palavras-chave: unidades de conservação; sistemas participativos; democratização do conhecimento. 
ABSTRACT: Scientific research is important for the management of protected areas, as it subsidizes the planning of actions for nature conservation and management. However, the results of the surveys are hardly used in day-to-day management. This paper aims to propose strategies to contribute to the use of scientific knowledge by the State Park of Ilha do Cardoso, identifying the current scenario of the management of the research and the expectations and difficulties regarding the access and communication of scientific knowledge. For this, semistructured interviews were conducted with researchers, employees and community members of the protected area. The result allowed the identification of problems related to the devaluation of the research bank, the lack of logistic support to the researchers and the monitoring of research by the protected areas; besides the inadequate formats of the research products for the effective use by the management; and the fear of the traditional community with studies that jeopardize its permanence in the Park. The solution of these problems is the understanding that scientific research is a fundamental and integral part of the routine of the protected areas, and the management must establish initiatives and strategies to improve the administrative scenario and bring the community closer to the research actions; as well as the researcher taking responsibility for the process of diffusion, popularization and democratization of scientific knowledge, taking into account the reality of the place and the mission of revealing sources for problem solving and opening new possibilities.

Keywords: protected areas; participatory systems; democratization of knowledge.

\section{Introdução}

As Unidades de Conservação - UCs - são espaços terrestres ou marinhos, instituídos pelo poder público, sujeitos a normas e regras especiais descritas pelo Sistema Nacional de Unidades de Conservação - SNUC, que assegura a representatividade de amostras significativas e ecologicamente viáveis das diferentes populações, habitat e ecossistemas, preservando o patrimônio biológico existente (Brasil, 2000).

O SNUC define dois regimes de proteção: o integral, que não permite a exploração direta dos recursos naturais, com exceção de casos previstos na referida lei; e o sustentável, que permite o uso direto e sustentável de parte dos recursos naturais, considerando restrições legais. Os Parques (Nacionais, Estaduais ou Municipais) são UCs de Proteção Integral, com o objetivo de preservação dos ecossistemas naturais de relevância ecológica e beleza cênica, possibilitando a realização de pes- quisas científicas, atividades educacionais, visitação pública e turismo ecológico (Brasil, 2000).

A pesquisa científica contribui para a proteção da biodiversidade e gera informações importantes, tais como, o status de conservação das espécies, habitat críticos e identificação de impactos e conflitos socioambientais e possibilita a proposição de parâmetros de monitoramento e manejo para a conservação, formas de uso sustentável dos recursos naturais, além de fomentar a criação de legislações, democratizar a informação e aumentar o interesse social em temáticas relacionadas ao meio ambiente (Battesini et al., 2013; Joly, 2014).

Todo processo de criação de um Parque é permeado por pesquisas científicas, que também subsidiam a tomada de decisão na rotina administrativa e a atualização do Plano de Manejo - PM, documento que fornece diretrizes, estratégias e ações de manejo, a partir de estudos e diagnósticos do meio físico, biológico e social, sendo recomendável a revisão a cada cinco anos (Joly, 2014). 
A maioria das UCs estaduais no Estado de São Paulo é gerida pela Fundação para a Conservação e Produção Florestal - FF, que está vinculada à Secretaria Estadual de Meio Ambiente. A pesquisa científica nestes espaços é administrada pelo Instituto Florestal - IF (São Paulo, 2006), por meio da Comissão Técnico-Científica-COTEC, que efetua o cadastramento, análise e acompanhamento dos projetos desenvolvidos nas UCs (Gallo Junior et al., 2014).

O Parque Estadual da Ilha do Cardoso - PEIC - protege um dos mais importantes hotspots brasileiros de biodiversidade, a Mata Atlântica. O Plano de Manejo da UC foi publicado em 2001 e prevê o Programa de Pesquisas Científicas, que estabelece metas para: estímulo à realização de estudos básicos e aplicados sobre meio físico, biótico e antrópico; cadastramento dos trabalhos de pesquisa realizados e em andamento, mantendo um banco de dados atualizado sobre os projetos de pesquisa desenvolvidos; a promoção do fluxo de informações junto às instituições de pesquisa e à COTEC, otimizando os procedimentos administrativos na gestão dos projetos de pesquisa; a criação e manutenção das infraestruturas de apoio para a realização dos trabalhos de pesquisa; e a capacitação permanente dos funcionários para o gerenciamento dos projetos e o acompanhamento dos pesquisadores em campo.

O objetivo do presente estudo é propor estratégias que viabilizem e facilitem a utilização do conhecimento científico pelo PEIC, identificando o cenário atual do gerenciamento da pesquisa e as expectativas e dificuldades referentes ao acesso e comunicação do conhecimento científico.

\section{Material e métodos}

\section{1. Área de estudo}

O PEIC está localizado entre as coordenadas $48^{\circ} 05^{\prime} 42^{\prime \prime} \mathrm{W}, 25^{\circ} 03^{\prime} 05^{\prime \prime}$ e $48^{\circ} 53^{\prime} 48^{\prime \prime}, 25^{\circ} 18^{\prime}$ $18^{\prime}$ S, no município de Cananeia, Litoral Sul do Estado de São Paulo (Figura 1), abrange uma área de aproximadamente 15.100 hectares e foi criado pelo Decreto n. ${ }^{\circ}$ 40.319, de 03 de julho de 1962 (SIMA, 2001). A região em que se insere o PEIC é conhecida como Vale do Ribeira, a qual abriga as áreas naturalmente mais preservadas do Estado.

O histórico de criação do Parque tem origem na justificativa de conter ações e empreendimentos imobiliários; paralisar a exploração de sambaquis, da fauna e da flora; criar um parque natural para estabelecer uma base de estudos; e implantar a estação de pesquisa do Instituto Oceanográfico da Universidade de São Paulo - IO-USP (SIMA, 2001; Moraes \& Lignon, 2012).

Na década de 1970, foi instalado na UC o Centro de Pesquisas Aplicadas em Recursos Naturais da Ilha do Cardoso-CEPARNIC, que contava com infraestrutura de alojamentos, casas para técnicos e laboratórios para o apoio e execução de trabalhos científicos e cursos especializados. Posteriormente, foi reformado e passou a integrar o Núcleo Perequê, que, atualmente, junto com o Núcleo do Marujá, fornecem estruturas de alojamento para pesquisadores, viabilizam o Programa de Voluntariado, atividades 
de visitação pública e educação ambiental (SIMA, 2001).

A ocupação humana no PEIC, datada desde a época do Brasil colonial, é reconhecida como povos tradicionais, sendo distribuída em sete comunidades caiçaras (Figura 1), com aproximadamente 392 moradores, e uma comunidade indígena, com cerca de 35 indígenas guaranis M’bia. Próximo ao Núcleo Perequê se encontra a comunidade do Pereirinha/ Itacuruçá com 11 famílias e, integrando o Núcleo Marujá, a comunidade do mesmo nome, com 58 famílias (Carvalho \& Schmitt, 2012; Valle, 2016).

Atualmente, as comunidades caiçaras têm na pesca, no turismo e nas atividades ligadas ao Par-

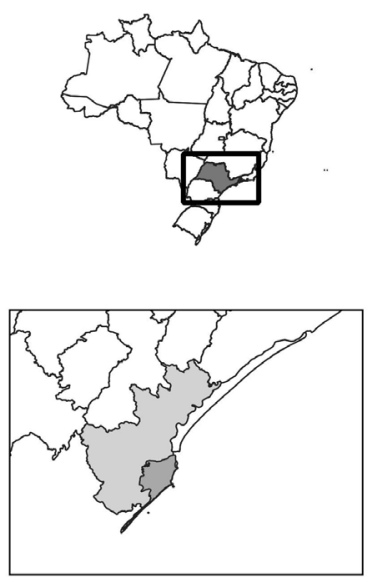

\section{Comunidades tradicionais do Parque Estadual da Ilha do Cardoso}

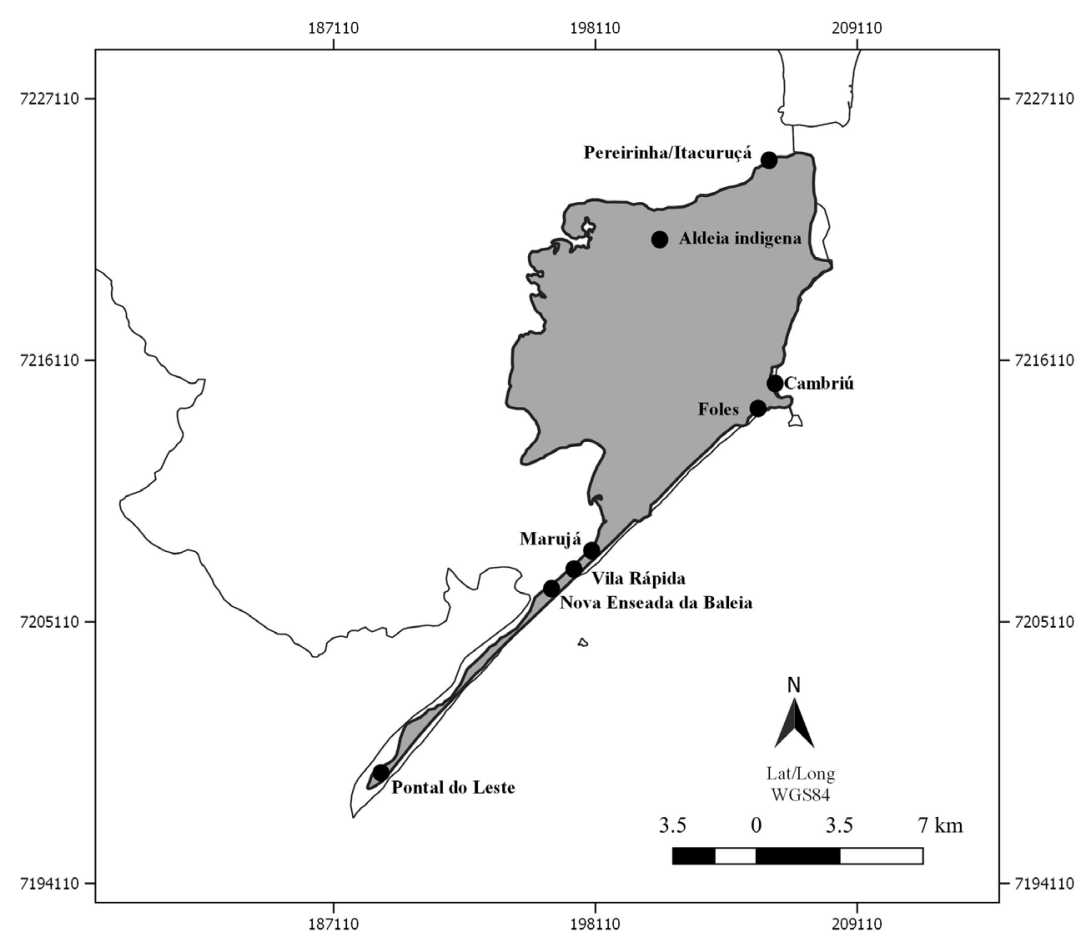

FIGURA 1 - Localização das comunidades tradicionais do Parque Estadual da Ilha do Cardoso.

FONTE: Elaborado pelos autores. 
que suas principais fontes econômicas (Miranda \& Hanazaki, 2008; Risso, 2016). E apesar de existirem conflitos sobre a ocupação no Parque, a gestão introduz formas participativas por meio da cogestão adaptativa (Schröter et al., 2018).

\subsection{Delineamento da pesquisa e procedimentos metodológicos}

Para a coleta de dados foram realizadas entrevistas semiestruturadas em profundidade e semiestruturada. A entrevista semiestruturada em profundidade foi o método escolhido para os atores que são facilmente contatáveis, pois é realizada presencialmente e permite simultaneamente a liberdade de expressão do entrevistado e a manutenção do foco pelo entrevistador através de um roteiro com as principais perguntas (Manzini, 2004; Chaer et al., 2011). Para os grupos que se encontram dispersos e distantes, a metodologia utilizada foi a entrevista semiestruturada, que apesar de não ser presencial, permite a liberdade de expressão dos atores através de perguntas abertas e garantem o direcionamento na temática junto às perguntas fechadas (Vieira et al., 2010).

As entrevistas presenciais foram realizadas entre março e abril de 2018, sendo individuais, anônimas, gravadas em áudio e posteriormente transcritas sem o auxílio de softwares de transcrição eletrônica.

Para as entrevistas, foram selecionados três grupos de estudo, sendo utilizado o método semiestruturado em profundidade para (a) as comunidades tradicionais e (b) os funcionários do PEIC; e o semiestruturado com (c) os pesquisadores. Os roteiros pré-definidos (questionários), foram exclusivos para cada grupo e buscaram identificar as concepções dos envolvidos sobre a pesquisa científica, o sistema de gestão da pesquisa no Parque e as principais dificuldades em acessar os resultados de trabalhos científicos.

A seleção dos membros das comunidades tradicionais foi realizada por amostragem não probabilística com intencionalidade (Manzini, 2004), incluindo moradores das comunidades do Pereirinha/Itacuruçá e Marujá, que estão próximas às estruturas de apoio à pesquisa que são fornecidas pelo Parque; maiores de 18 anos; não analfabetos; atuação relevante no conselho consultivo do Parque e na associação de moradores; e equidade de gêneros. Também foi utilizada a metodologia snowball (bola de neve), em que cada entrevistado indica novos participantes que, por sua vez, indicam outros e assim sucessivamente, sendo o processo finalizado a partir do ponto de saturação, que é atingido quando os novos entrevistados passam a repetir os conteúdos já obtidos em entrevistas anteriores, sem acrescentar novas informações relevantes à pesquisa (Baldin \& Munhoz, 2011; Vinuto, 2014; Schröte et al., 2018). O primeiro entrevistado de cada um dos locais foi indicado pelos funcionários do Parque, uma vez que estes possuem conhecimento sobre as comunidades.

A seleção dos funcionários do Parque buscou incluir o depoimento de toda a equipe, abrangendo o gestor, concursados públicos, contratados e prestadores de serviços, que totalizam um quadro profissional de 14 pessoas.

Para os pesquisadores, foi utilizado o banco de dados dos projetos de pesquisas aprovados pela COTEC, no qual foram selecionados todos que realizaram estudos (concluídos ou em execução) de 1998 a 2018, totalizando 117 pesquisadores. 
As entrevistas semiestruturadas foram realizadas online, através da ferramenta formulário do Google e com divulgação via $e$-mail.

\subsection{Análise de dados}

A análise de dados foi realizada com base na técnica descrita por Moraes (1999), que busca descrever e interpretar os conteúdos das entrevistas, conduzindo a descrições qualitativas ou quantitativas, atingindo a compreensão dos significados presentes nos discursos. O processo foi dividido em cinco etapas: preparação; unitarização; categorização; descrição; e interpretação.

A etapa de preparação consistiu na leitura dos conteúdos das entrevistas para identificação de informações condizentes com os objetivos da pesquisa. Na unitarização, foram definidos os trechos dos discursos com informações passíveis de análise. Os conteúdos comuns nas entrevistas de cada grupo de estudo foram categorizados, e as informações com caráter quantitativo foram descritas em tabelas e gráficos; e as com caráter qualitativo foram compiladas em "citações diretas" capazes de expressar o conjunto de significados presentes nas demais unidades de análise. Na última etapa, buscou-se a compreensão dos resultados através da interpretação, sendo a análise restrita ao nível manifesto.

Para diagnosticar a percepção do conceito e importância das pesquisas científicas no PEIC, foram analisadas as entrevistas com o gestor, funcionários e comunidade de acordo com as definições de Ciribelli (2003) e Praça (2015), que descrevem a pesquisa científica como uma problemática solucionada dentro de um objeto de investigação, que é definido, examinado, avaliado e analisado criticamente, pressupondo métodos próprios, procedimentos sistemáticos e conhecimentos específicos a respeito da temática abordada.

Para descrever o cenário atual da gestão administrativa da pesquisa científica, foram analisadas as entrevistas com os pesquisadores, gestor e funcionários. E para entender as expectativas e dificuldades referentes ao acesso e comunicação foram avaliadas as entrevistas com o gestor, funcionários, comunidade tradicional e pesquisadores.

\section{Resultados e discussão}

\subsection{Percepção sobre o conceito e importância da pesquisa científica}

Dos funcionários do PEIC, incluindo o gestor, foram entrevistados $93 \%$ de toda a equipe, o perfil predominante foi o sexo masculino (85\%), 51 anos ou mais (38\%) e taxa de escolaridade incidindo no ensino médio incompleto (29\%) e superior completo $(29 \%)$.

A maior parte da equipe do Parque (75\%) conseguiu formular alguma definição de pesquisa científica, e até os que não souberam conceituar entendem a importância da pesquisa científica para a conservação, reconhecendo que o conhecimento pode auxiliar nas atribuições do trabalho, no crescimento profissional e até mesmo em aspectos pessoais, entendendo-o como fonte de transformação do olhar sobre a vida.

No que se refere à comunidade tradicional, foram entrevistados 23 moradores, sendo 13 do Pereirinha/Itacuruçá e 10 do Marujá, 61\% homens, de 41 a 50 anos (35\%) e taxa de escolaridade in- 
cidindo no ensino fundamental incompleto (43\%). A maioria dos moradores alegou já ter participado ou acompanhado o desenvolvimento de pesquisas no Parque $(73 \%)$, incluindo atividades de coleta, apoio logístico, monitoria/guia local e troca de informações sobre o objeto de estudo. Dos que conceituaram (48\%) o que é uma pesquisa científica, tiveram definições atreladas às ciências naturais, com exemplos da fauna e flora (Figura 2). Este fato pode estar relacionado às experiências práticas dos sujeitos, que descreveram sua participação, auxílio ou contribuição em pesquisas científicas exclusivamente nestas temáticas.

Tendo em vista a distância da Ilha dos centros urbanos da região, as pesquisas científicas podem ser uma importante ferramenta de acesso ao conhecimento para os moradores. A socialização do conhecimento científico com a sociedade civil permite o entendimento dos fenômenos científicos e tecnológicos, desde os mais complexos até os que fazem parte do dia a dia (Rendeiro \& Gonçal- ves, 2014). Contudo, para que a informação seja assimilada e entendida, transformando-se em conhecimento com apropriação de termos, conceitos, normas e métodos de todas as formas de ciência, é necessária a instalação de um debate democrático e introduzido por sentido crítico.

A importância da pesquisa científica para a comunidade tradicional é reconhecida por todos, sendo alguns dos benefícios citados: propostas para o uso sustentável dos recursos naturais; reconhecimento da cultura e saberes caiçara; e complementação na formação educacional dos moradores, monitores ambientais e guias locais que trabalham com o turismo. Apesar de acreditarem nestes ganhos positivos, apenas $13 \%$ dos moradores entrevistados conseguiram mencionar ações concretas que as pesquisas podem proporcionar, e $35 \%$ colocou que a pesquisa também pode acarretar em restrições ao modo de vida local, incluindo realocação das famílias, limitação ao turismo e ao uso dos recursos naturais.

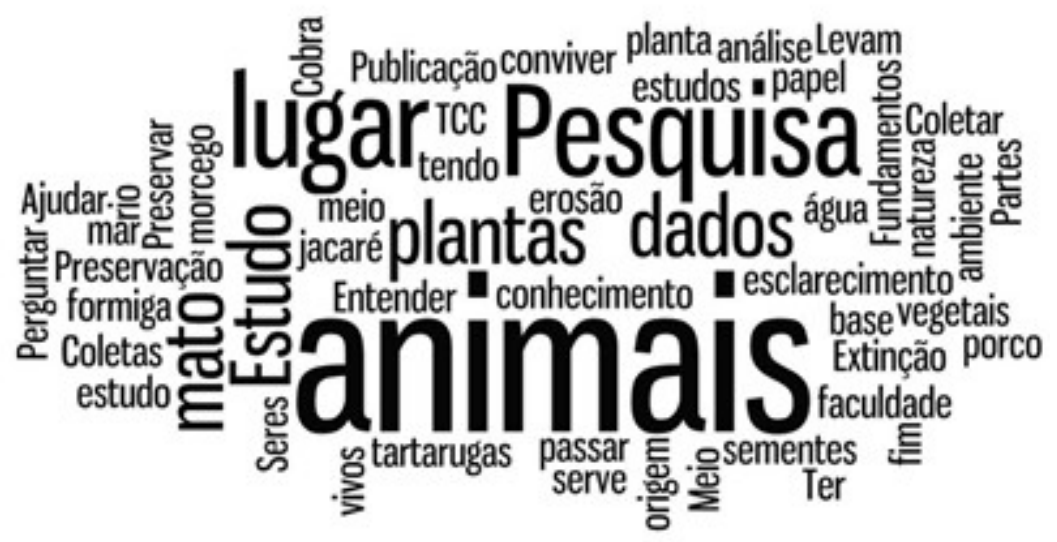

FIGURA 2 - Nuvem das palavras mais citadas pelos moradores do PEIC quando questionados sobre o conceito de pesquisa científica. FONTE: Dados da pesquisa. 
Estes resultados, juntamente com o histórico de criação do PEIC, evidenciam a necessidade dos produtos das pesquisas serem convertidos em ações concretas sob o olhar da comunidade, tendo em vista que o distanciamento e receio entre as partes pode ampliar a disseminação de preocupações que criam barreiras para o desenvolvimento de novas pesquisas no local.

A gestão da UC e os pesquisadores, junto às Universidades que representam, devem articular projetos de extensão universitária que estimulem permanente e sistematicamente a realização de cursos, eventos, oficinas, prestação de serviços e outras atividades, que se comprometam com a transformação social, aproximando a produção e a transmissão de conhecimento dos efetivos destinatários, cuidando para corrigir, nesse processo, a assimétrica e desigual apropriação do conhecimento, das ciências e das tecnologias, considerando a intrínseca relação das comunidades tradicionais com o seu território, que é vivenciado a partir do conhecimento local, onde função e valores simbólicos coexistem através de uma cultura marcada por crenças, danças, agricultura, pesca, além do sentimento de pertencimento ao local.

\subsection{Gestão das pesquisas científicas}

Dos 117 questionários enviados aos pesquisadores, a devolutiva foi de apenas $23 \%$, sendo a maioria dos pesquisadores vinculados à instituições de ensino localizadas no Estado de São Paulo (92\%), finalizaram os estudos na UC no período de 2015 a 2017 (33\%), ou ainda estão em andamento (26\%), com as áreas de maior concentração voltadas à ecologia, fauna e flora (Figura 3).

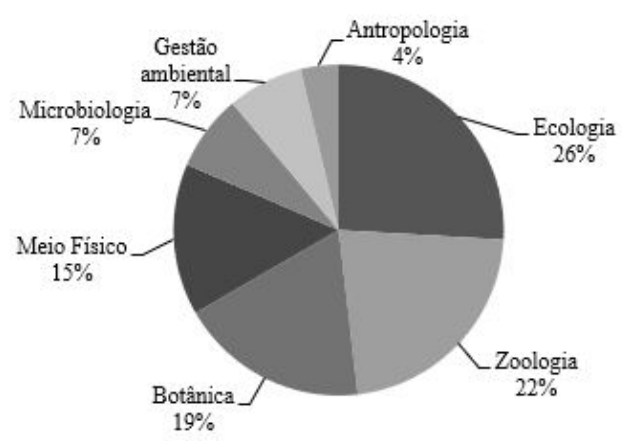

FIGURA 3 - Áreas do conhecimento das pesquisas desenvolvidas no Parque Estadual da Ilha do Cardoso pelos pesquisadores entrevistados. FONTE: Dados da pesquisa.

A ferramenta utilizada para o gerenciamento dos projetos de pesquisas no PEIC é um banco de dados no Programa Office Excel. O banco de dados é um dos pilares básicos para a gestão do conhecimento, pois facilita o planejamento, controle, coordenação e análise de grandes volumes de dados (Silva et al., 2015; Gaspar et al., 2016).

Nos Programas de Gestão do Plano de Manejo do PEIC, formalizado em 2001 e sem atualizações posteriores, um dos objetivos do Programa de Pesquisa Científica é cadastrar os trabalhos de pesquisa realizados e em andamento, agilizando o fluxo de informações entre a Unidade, instituições de pesquisa e IF. A alimentação constante deste sistema fomenta ações técnicas, facilita a identificação de eventuais projetos não formalizados na COTEC e dá respaldos para a atualização de temáticas prioritárias contidas no PM, buscando promover um diálogo junto ao IF para o desenvolvimento de parcerias com agências de fomento à pesquisa, que podem priorizar linhas de pesquisas coerentes com as demandas dos territórios protegidos no Estado. 
Contudo, atualmente o banco de dados da UC encontra-se desatualizado e com defasagem de informações, o que dificulta o cumprimento do objetivo do Programa de Pesquisa Científica do PM, além de impossibilitar a identificação das lacunas do conhecimento, territórios prioritários para pesquisas e sobreposição de projetos. Além disso, mesmo com a elevada demanda e oportunidade de pesquisas, o PEIC carece de condições logísticas adequadas à pesquisa. A criação e a manutenção das infraestruturas de apoio ao pesquisador também é um dos objetivos listados no Programa de Pesquisas do PM, porém a falta de apoio institucional é materializada na defasagem de recursos humanos, falta de materiais para o desenvolvimento das atividades, e condições precárias da infraestrutura para hospedagem dos pesquisadores.

De acordo com Reis \& Queiroz (2017), essa realidade é recorrente em muitos Parques, que se encontram em situação de abandono e necessitando de investimentos em pessoal capacitado, infraestrutura e equipamentos. Promover condições para a realização das pesquisas garante o sucesso da mesma e resultam na facilitação da interface comunidade, gestão administrativa e pesquisador, tornando-se um canal para ações de comando e controle da gestão, que exigem parcerias e retornos para a UC.

Nas entrevistas com os funcionários do PEIC, foi relatado que poucos pesquisadores informam sobre o início dos trabalhos de campo e que há pouco acompanhamento das atividades in loco. A carta de aprovação do projeto pela COTEC solicita o agendamento prévio de 15 dias junto à administração da UC para as atividades de campo, porém a falta de recursos humanos e a elevada extensão territorial do Parque resultam na ausência de monitoramento e de aplicação de sanções pelo descumprimento das regras.

A comunicação quanto aos trabalhos de campo, bem como a submissão do projeto de pesquisa à COTEC, é responsabilidade do pesquisador, cabendo às instituições de ensino e pesquisa, o alerta e o reforço quanto aos procedimentos éticos da pesquisa e conhecimento dos regramentos da UC. Para a gestão, a alternativa é a comunicação contínua das regras via pareceres de análises de projetos junto a COTEC, realização de palestras e demais ações de divulgação, além de unir esforços para a capacitação permanente dos funcionários para o gerenciamento dos projetos de pesquisa e acompanhamento dos pesquisadores em campo, conforme previsto no Programa de Pesquisas Científicas do PM.

A gestão (informação verbal) ${ }^{1}$ também acrescenta que precisa avançar na gestão do conhecimento, pensando em estratégias para que os pesquisadores inicialmente retornem com os resultados quando a pesquisa é finalizada:
A principal dificuldade é que os resultados cheguem. Segundo é que a gente tenha condição de conhecer os resultados e terceiro é que a partir daquele conhe- cimento a gente gere estratégias para a conservação [...] às vezes tem pesquisa que descobriu espécies novas, tem publicação, mas a Unidade não foi avi- sada, não fica sabendo. Quando chega, dependendo da forma que chega, se estivermos com a rotina atri- bulada de atividades e trabalhos, é dificil tirar um tempo para a leitura, análise e depois desenvolver algo sobre (informação verbal) ${ }^{1}$

\footnotetext{
${ }^{1}$ Entrevista concedida aos autores entre março e abril de 2018, com asseguração do anonimato do participante e aprovação do Comitê de Ética em Pesquisa.
} 
Para os funcionários do PEIC, a devolutiva final das pesquisas é mínima quando comparada ao número de projetos que são aprovados pela COTEC, porém $50 \%$ alegou ter contato com alguma forma de devolutiva, sendo a maioria através de relatórios finais, conversas informais com os pesquisadores e palestras no Conselho Consultivo.

A partir da consolidação do banco de dados dos projetos de pesquisa, o Parque pode entrar em contato direto com os pesquisadores cujos estudos foram finalizados e possam ter resultados relevantes à gestão ou à comunidade tradicional, além disso, pode reportar a COTEC a pendência quanto ao relatório final da pesquisa.

Para a COTEC, sugere-se o desenvolvimento de uma plataforma online, a exemplo da Plataforma Brasil, gerida pela Comissão Nacional de Ética em Pesquisa - CONEP - do Ministério da Saúde, que consiste em uma base nacional e unificada para registro das pesquisas envolvendo seres humanos e permite a apresentação dos documentos da pesquisa por meio digital, possibilitando o acompanhamento desde a submissão até a aprovação final, incluindo as fases de campo e envio dos relatórios parciais e finais (Assessoria Plataforma Brasil, 2018). O sistema também propicia o acesso aos dados públicos de todas as pesquisas aprovadas e emite parecer de pendência ou suspensão aos projetos que não seguem as diretrizes éticas ou quando não são inseridas as documentações exigidas (Baptista et al., 2015). O Instituto Chico Mendes de Conservação da Biodiversidade (ICMBio), entidade gestora das UCs Federais, já adota um sistema online para análise e aprovação de pesquisas.
Dos pesquisadores entrevistados, $74 \%$ alegou incluir no cronograma da pesquisa o retorno dos resultados para a gestão e dizem acreditar que a função de efetivar a devolução do conhecimento é de todos os envolvidos, ou seja, pesquisador (orientado e orientador) e gestão da UC.

Dos 20 entrevistados com trabalhos concluídos, 15\% não apresentaram devolutiva dos resultados. Os que realizaram, mencionaram não haver dificuldade para o encaminhamento do trabalho final $(65 \%)$ e, quando questionados sobre as estratégias utilizadas para o encaminhamento dos resultados à gestão, foram considerados com unanimidade formatos acadêmicos, como relatórios, artigos científicos, dissertações e teses.

As pesquisas acadêmicas são extensas, complexas e abordam temáticas e conceitos específicos e variados, sendo incoerentes com a rotina administrativa das UCs, que é dinâmica e atribulada de tarefas e demandas. Além disso, o quadro de funcionários do Parque conta com diversos níveis de escolaridade e formações, que não os capacita para a pluralidade de pesquisas que possam ser desenvolvidas no território. A equipe do PEIC (informação verbal) ${ }^{2}$ relatou ter dificuldade para interpretar os resultados das pesquisas e ressalta que deveriam ser resumidos, em linguagem simples e coerente com a rotina da UC:

O leque de possibilidades de pesquisas é muito grande. Recebemos pesquisas de genética, fauna, ecologia, comunidades tradicionais, gestão. Você tem que avançar em áreas do conhecimento que vão além da sua formação. E tem a questão dos formatos. [...] Receber em um ano 24 pesquisas, ver o resultado gerado por cada uma e utilizar na gestão é muito difícil com a estrutura que temos. Talvez se tivéssemos uma equipe focada nisso, seria 
possivel, mas a demanda do dia a dia consome. Seria ótimo se as informações chegassem resumidas para a primeira análise da gestão (informação verbal) ${ }^{2}$

De acordo com Moretti et al. (2013), dos 140 questionários aplicados em gestores de UCs nas diversas regiões do Brasil, 54\% relataram nunca ou raramente utilizar publicações científicas para amparar o planejamento da gestão, sendo as maiores dificuldades a interpretação dos resultados; acesso aos trabalhos; falta de recursos, tempo e pessoal; pouca base de dados no local de atuação; e dissociação entre prática e ciência.

Entretanto, é consenso o benefício que as pesquisas podem trazer para a conservação e, apesar das dificuldades no gerenciamento das pesquisas no PEIC, a gestão (informação verbal) ${ }^{3}$ acrescenta exemplos práticos, de projetos bem estruturados que subsidiaram ações de sucesso:

Uma pesquisa bem estruturada e desenvolvida em conjunto com a gestão, pode trazer subsídios pra gerar ações. [...] Algumas conseguimos fazer uso. Temos muitas pesquisas de longa data, relacionadas ao Sotalia guianensis e muitos dos dados foram utilizados para o ordenamento da visitação pública na praia do Pereirinha (informação verbal) ${ }^{3}$

Entendendo a importância da pesquisa para a gestão, o Conselho Gestor do PEIC disponibiliza cadeira fixa para as instituições de pesquisa, que devem assumir o pleito e ocupar estes espaços de forma atuante e participativa, tendo em vista que são vetores do desenvolvimento econômico e social, tendo como missão levar a pesquisa à sociedade, revelando fontes para a resolução de problemas e abertura de novas possibilidades.

Dos pesquisadores entrevistados, $41 \%$ alegou que o resultado da sua pesquisa pode contribuir com ações diretas para a gestão, 33\% alegou retorno indireto e $26 \%$ não soube responder ou não respondeu. Em contrapartida, pesquisadores (67\%) e funcionários do PEIC ( $83 \%$ ) consideram que a contribuição da pesquisa científica para a gestão das UCs não é efetiva, devido a problemas na comunicação e falta de cobrança, monitoramento e apoio à pesquisa, acarretando em barreiras dialógicas e em resultados finais com formatos incoerentes para a rotina administrativa.

Com base na necessidade de uma documentação que forneça as informações das pesquisas de forma dinâmica e rápida, sugere-se o modelo de relatório utilizado pela Fundação do Meio Ambiente - FATMA, que gerencia as pesquisas nas UCs do Estado de Santa Catarina (FATMA, 2018). O modelo compartimenta os resultados das pesquisas buscando sintetizar, identificar e ressaltar as informações relevantes à gestão das UCs. O modelo pode ser transposto para a ferramenta formulário do Google, sendo enviado por e-mail aos pesquisadores. A COTEC também pode utilizar o modelo para compor um sistema de gerenciamento online simplificado.

A informação é a matéria-prima para o conhecimento e estão intimamente conectadas, sendo parte de um mesmo processo organizacional. O gerenciamento das informações científicas deve ir além

\footnotetext{
${ }^{2}$ Entrevista concedida aos autores entre março e abril de 2018, com asseguração do anonimato do participante e aprovação do Comitê de Ética em Pesquisa.

${ }^{3}$ Entrevista concedida aos autores entre março e abril de 2018, com asseguração do anonimato do participante e aprovação do Comitê de Ética em Pesquisa.
} 
da análise de projetos, visto que o projeto consiste apenas na etapa inicial do desenvolvimento de uma pesquisa. O fluxo de informações deve ser finalizado com a inserção das conclusões, para que então seja gerado conhecimento, que será transmitido e distribuído com o intuito de propiciar planos e visões estratégicas para a materialização de ações (Pessoa et al., 2016). Gerir conhecimento envolve tempo, pessoas, informação e processos, cabendo à UC reconhecer e entender a pesquisa científica como uma ferramenta fundamental e norteadora para as ações de conservação, inserindo-a na rotina administrativa.

\subsection{Democratização e popularização do conhecimento científico}

Sobre a acessibilidade aos resultados das pesquisas para a comunidade tradicional do PEIC, $41 \%$ dos pesquisadores entrevistados não realizaram nenhuma forma de devolutiva, e os que tiveram esta preocupação, utilizaram na maioria das vezes relatórios, resumos, artigos científicos, rodas de conversa e palestras, alegando que os mesmos foram adaptados para a linguagem do público-alvo.

Dos moradores, $83 \%$ alegaram ter recebido devolutiva dos resultados das pesquisas, entre as formas, foram citados: livros, cartilhas, vídeos, conversas informais, resumos e apresentações via Conselho ou Associação de Moradores. Destes, 58\% acreditam que a metodologia utilizada foi satisfatória, $21 \%$ disse ter sido insatisfatória e 21\% não respondeu ou não soube responder. É adequado que o pesquisador realize a devolutiva dos resultados através de materiais escritos, como artigos, resumos, livros, vídeos e cartilhas, pois são fontes que possibilitam a visita constante ao conteúdo e certificam a informação. Contudo, é fundamental que o pesquisador ajuste o documento à linguagem do público-alvo e complemente a devolutiva com o discurso oral, visando sanar dúvidas e unir esforços junto à comunidade para subsidiar ações de conservação coerentes ao contexto sociocultural do local. Conforme explica um morador da comunidade tradicional do PEIC (informação verbal) $^{4}$

Quando você está conversando com pessoas que tem a parte técnica e você tem a parte prática, as dificuldades de comunicação aparecem. Essas duas coisas não se cruzam para um bom entendimento. A parte teórica talvez vá entender um pouco da nossa parte, mas a nossa parte não vai entender a teoria facilmente. É uma coisa complicada de assimilar [...]. Cada pesquisador tem um modo de ver as coisas. Tem pesquisador que acredita nas histórias do local e tem pesquisador que acredita só na teoria [...]. Eu acho que as palavras é a maior dificuldade. A linguagem é diferente, não é do nosso dia a dia (informação verbal $)^{4}$.

Divulgar ciência não é transcrevê-la de uma linguagem para outra, mas construir uma ponte entre o lugar da ciência e os outros lugares (Baptista, 2015). Desta forma, não se trata apenas de tornar o discurso científico acessível, mas considerar o saber do grupo, com seus componentes culturais e políticos (Cavalcante, 2011; Souza \& Kurtz, 2014; Cuffa et al., 2016).

Sobre as possíveis ações que as pesquisas podem contribuir para a comunidade, $48 \%$ dos moradores entrevistados não identificaram formas de retorno que possam gerar ações concretas, e $26 \%$

\footnotetext{
${ }^{4}$ Entrevista concedida aos autores entre março e abril de 2018, com asseguração do anonimato do participante e aprovação do Comitê de Ética em Pesquisa.
} 
mencionaram enriquecimento técnico aos monitores e guias locais; valorização do conhecimento etnobotânico; fortalecimento comunitário e das lideranças para o desenvolvimento do turismo; benefícios para a gestão compartilhada e visibilidade das comunidades nos processos de tomada de decisão; e agregar conhecimento para ações de educação ambiental.

O caráter qualitativo da comunicação da ciência nos espaços não formais tem o potencial de promover a motivação para um futuro aprofundamento ou, em outros casos, a mudança de atitudes com o aprendizado formal, mas para isso é necessário explorar os temas de forma que o público os transponha para a sua vida (Cazelli et al., 2015).

A gestão da UC tem o compromisso de informar a comunidade sobre as pesquisas científicas produzidas no território, além de incentivar a troca de experiências entre os envolvidos (técnicos, pesquisadores e comunidade). As reuniões do Conselho Consultivo podem atuar como espaços para debater e informar sobre os estudos em andamento ou finalizados no PEIC, conforme indicado pelo Programa de Pesquisas Científicas do PM.

A equipe da UC relatou que muitos pesquisadores possuem resistência para realizar ações de comunicação com a comunidade, mesmo quando solicitados formalmente. Apesar de caber à gestão administrativa ser ponte para a troca de conhecimentos, a concretização só é possível quando existe participação ativa do pesquisador, entendendo que a cultura também é um bem que deve ser preservado. $\mathrm{O}$ desafio consiste em abrir espaço para dialogar e compreender as teorias subentendidas nas práticas dessas comunidades, originando condições para a troca de saberes, que resultam em modificações dos pontos de vista, atitudes e posturas para o uso sustentável do território.
Todos os pesquisadores entrevistados reconhecem a importância de manter o diálogo inclusivo com a sociedade, e $82 \%$ alegam que as instituições que representam promovem atividades de extensão, porém 33\% relata que não é a prioridade da instituição, sendo as publicações de artigos científicos, palestras, simpósios e congressos as principais formas de incentivo para devolutivas junto à sociedade civil.

As instituições de pesquisa estão cada vez mais focadas na valorização excessiva da produção científico-acadêmica, conferindo destaque profissional àqueles com o maior número de artigos publicados (Droescher \& Silva, 2014). A produção científica é importante, contudo, o conhecimento não deve ser pautado apenas neste contexto, em que os pesquisadores são reféns dos sistemas de avaliação, investimentos e recursos disponíveis, desconsiderando o compromisso maior da ciência de elevar o conhecimento para a melhoria da vida individual e coletiva em suas múltiplas dimensões e interfaces.

\section{Conclusão}

A defasagem no uso do banco de dados dos projetos de pesquisa por parte da gestão do PEIC resulta no desperdício de informações, impedindo o estabelecimento de estratégias para o controle dos resultados. O investimento na capacitação dos funcionários do Parque no que tange à gestão administrativa da pesquisa científica e ao incentivo institucional, de modo a estabelecer parcerias junto às agências de fomento à pesquisa e universidades, são fatores fundamentais para o avanço no controle dos resultados, na identificação dos temas prioritários e no preenchimento das lacunas de conhecimento. 
Modelos de gestão do conhecimento, como o utilizado pela FATMA e pela Plataforma Brasil, que, de forma colaborativa, reúnem o conteúdo das pesquisas e digitalizam a informação em sistemas online, são boas opções para as Unidades de Conservação (UCs), pois cria-se um banco de dados digital centralizado e padronizado, que pode ser facilmente acessado e analisado por diferentes perspectivas, diminuindo o esforço direto das UCs no gerenciamento dos projetos de pesquisa e direcionando esforços para a gestão do conhecimento e suas lacunas.

O PEIC deve estabelecer estratégias para facilitar e cobrar o retorno dos resultados das pesquisas, além de promover e incentivar ações junto aos funcionários e comunidade, para debater informações que sejam relevantes ao território, assumindo a responsabilidade de incorporar a gestão da informação e do conhecimento científico na rotina. Porém, o processo torna-se enriquecedor quando o pesquisador entende a dinâmica da gestão e suas particularidades, concebendo seu encargo para a democratização e popularização do conhecimento. Os Centros Universitários devem institucionalizar a responsabilidade de devolver para a sociedade seus conhecimentos adquiridos, construindo protocolos/ normas para tal, visto que não há como esperar que o aluno/pesquisador desempenhe o papel da extensão universitária, sem o apoio e incentivo da instituição.

A relação entre UCs e pesquisadores deve ser uma via de mão dupla, possibilitando o apoio à pesquisa, acompanhado pelo desenvolvimento de estudos que respondam as questões de interesse do território, incluindo o retorno do conhecimento.

A importância da pesquisa para as comunidades tradicionais é um cenário complexo, uma vez que, apesar de acreditarem nos ganhos positivos e considerarem importante a realização das pesquisas, também apresentam receios quanto a possíveis restrições que a ciência pode trazer ao modo de vida local. A promoção de uma agenda contínua de atividades, encontros, oficinas e cursos para dialogar e compartilhar saberes, inserindo a comunidade em um processo emancipatório e crítico, coerente com a realidade local, é o caminho para a interface entre pesquisa científica, áreas protegidas e sociedade.

\section{Referências}

Assessoria Plataforma Brasil. Manual do Usuário: Pesquisador. Versão 3.2. 2018. Disponível em: $<$ http://conselho. saude.gov.br/images/comissoes/conep/documentos/PB/ MANUAL_PESQUISADOR.pdf>. Acesso em: fev. 2019.

Baldin, N.; Munhoz, E. M. B. Educação ambiental comunitária: uma experiência com a técnica de pesquisa Snowball (bola de neve). Revista Eletrônica do Mestrado de Educação Ambiental, 27, 46-60, 2011. Disponível em: https://periodicos.furg.br/remea/article/view/3193/1855

Baptista, V. A popularização da ciência a partir da análise do Programa "Ciência na sociedade ciência na escola" desenvolvendo pela Universidade Federal do Rio Grande do Sul. Porto Alegre, Dissertação (Mestrado em educação em ciências) - Departamento de Bioquímica, Universidade Federal do Rio Grande do Sul, 2015.

Battesini, M. D.; Santos, C. Z. A.; Neto, J. O. M.; Gomes, L. J. Publicações acadêmicas das Unidades de Conservação no Estado de Sergipe, Brasil. Interciencia, 38(1), 67-72, 2013.

Brasil. Lei Federal n 9.985, de 18 de julho de 2000. Dispõe sobre o Sistema Nacional de Unidades de Conservação (SNUC). Brasília: DOU de 19/7/2000.

Carvalho, M. C. P. de; Schmitt, A. Relatório técnico-científico para identificação de famílias tradicionais presentes no Parque Estadual da Ilha do Cardoso. Elaborado em atendimento ao Termo de Referência emitido pela Fundação Florestal, 2012. Disponível em: <http://lcb.fflch.usp.br/sites/ lcb.fflch.usp.br/files/upload/paginas/Laudo_Antropologi- 
co_PEIC.pdf>. Acesso em: mar. 2019.

Cavalcante, J. Análise das práticas de Gestão do Conhecimento em uma empresa de serviços de assessoria e educação profissional. Qualitas Revista Eletrônica, 12(2), 1-17, 2011. Disponível em: http://revista.uepb.edu.br/index.php/ qualitas/article/download/950/637

Cazelli, S.; Coimbra, C. A. Q.; Gomes, I. L.; Valente, M. E. Inclusão social e a audiência estimulada em um museu de ciência. Museologia \& Interdiciplinariedade, 4(7), 203-223, 2015. doi: 10.26512/museologia.v4i7.16780

Chaer, G.; Diniz, R. R. P.; Ribeiro, e. A. A técnica do questionário na pesquisa educacional. Revista Evidência, 7(7), 251-266, 2011. Disponível em: http://www.educadores. diaadia.pr.gov.br/arquivos/File/maio2013/sociologia_artigos/pesqusia_social.pdf

Ciribelli, M. C. Como elaborar uma dissertação de Mestrado através da pesquisa cientifica. Rio de Janeiro: Editora 7 Letras, 2003.

Cuffa, D. de; Zago, C.; Zarelli, P. R.; Mello, G. R. de. O Impacto da governança corporativa eletrônica na gestão do conhecimento. Navus: Gestão e Tecnologia, 6(4), 98-107, 2016. doi: 10.22279/navus.2016.v6n4.p98-107.421

Droescher, F. D.; Silva, E. L. da. O pesquisador e a produção científica. Perspectivas em Ciência da Informação, 19(1), 10-189, 2014. Disponível em: http://portaldeperiodicos.eci. ufmg.br/index.php/pci/article/view/1899

FATMA - Fundação do Meio Ambiente. Pesquisas em UCs. Disponível em: <http://www.fatma.sc.gov.br/conteudo/ pesquisas-em-ucs $>$. Acesso em: ago. 2018.

Gallo Junior, U.; Santiago, C. de M.; Robim, M. de J.; Sousa, M. R. de. Aspectos da gestão da pesquisa científica no Parque Estadual da Ilha Anchieta - São Paulo, Brasil. Ciência \& Tecnologia, 1(1), 93, 2014. Disponível em: http:// www.periodicos.rc.biblioteca.unesp.br/index.php/olam/ article/view/8912

Gaspar, M. A.; Santos, S. A. dos; Donaire, D.; Kuniyoshi, M. S.; Prearo, L. C. Gestão do conhecimento em empresas atuantes na indústria de software no Brasil: um estudo das práticas e ferramentas utilizadas. Informação \& Sociedade: Estudos, 26(1), 151-166, 2016. Disponível em: https:// periodicos.ufpb.br/ojs2/index.php/ies/article/view/16360

Joly, C. Pesquisa cientifica em Áreas Protegidas do Litoral Norte de São Paulo: limitações e perspectivas visando a conservação. Campinas, Tese (Doutorado em Aspectos Sociais de Sustentabilidade e Conservação) - UNICAMP, 2014.

Manzini, E. J. Entrevista semi-estruturada: análise de objetivos e de roteiros. In: II Seminário Internacional sobre Pesquisa e Estudos Qualitativos. Bauru, 25 de mar., 2004.

Miranda, T. M.; Hanazaki, N. Conhecimento e uso de recursos vegetais de restinga por comunidades das ilhas do Cardoso (SP) e de Santa Catarina (SC), Brasil. Acta Botanica Brasilica, 22(1), 203-215, 2008. doi: 10.1590/ S0102-33062008000100020

Moraes, H. M. T.; Lignon, M. C. Caracterizando os Visitantes do Parque Estadual da Ilha do Cardoso (SP): subsídio para o planejamento de atividades turística-educacional em áreas de manguezal. Revista Brasileira de Ecoturismo, 5(3), 648-665, 2012. doi: 10.34024/rbecotur.2012.v5.6146

Moraes, R. Análise de conteúdo. Revista Educação, 22 (37), 7-32, 1999.

Moretti, M.; Giehl, E. L. H.; Batalha, M. A. Aplicação de informações científicas na gestão de unidades de conservação no Brasil. In: IV Congresso Brasileiro de Gestão Ambiental. Salvador, 25 de nov., 2013.

Pessoa, C. R. M.; Nassif, M. E.; Silva, A. M. da; Marques, M. E. Da gestão de TI à gestão de informação e tecnologia: uma abordagem teórica da evolução do conceito. In: XVII Encontro Nacional de Pesquisa em Ciência da Informação. Bahia, 20 de nov., 2016.

Praça, F. S. G. Metodologia da pesquisa científica: organização estrutural e os desafios para redigir o trabalho de conclusão. Revista Eletrônica "Diálogos Acadêmicos", 8(1), 72-87, 2015. Disponível em: http://uniesp.edu.br/ sites/_biblioteca/revistas/20170627112856.pdf

Reis, A. F.; Queiroz, O. T. M. M. Concessões nas Unidades de Conservação do Estado de São Paulo: reflexões, oportunidades e desafios. Revista Brasileira de Ecoturismo, 10(2), 376-387, 2017. doi: 10.34024/rbecotur.2017.v10.6572

Rendeiro, M. F. B.; Gonçalves, C. B. Divulgação e popula- 
rização da ciência: relato de experiência do Projeto "Ciência às 7 e meia". Revista Areté: Revista Amazônica de Ensino de Ciências, 7(13), 222-231, 2014. Disponível em: http:// periodicos.uea.edu.br/index.php/arete/article/view/117

Risso, L. C. Participação social em Unidades de Conservação: o caso do Parque Estadual da Ilha do Cardoso (São Paulo, Brasil). Ateliê Geográfico, 10(3), 109-128, 2016. doi: 10.5216/ag.v10i3.34672

São Paulo. Decreto $n^{\circ}$ 51.453, de 29 de dezembro de 2006. Cria o Sistema Estadual de Florestas - SIEFLOR e dá providências correlatas. São Paulo: DOU de 30/12/2006.

Schröter, B.; Sessin-Dilascio, K.; Jericó-Daminello, C.; Sattler, C. De espectadores impotentes a cogestores adaptativos: uma comunidade no Parque Estadual da Ilha do Cardoso (Cananéia, São Paulo, Brasil). Revista Brasileira de Gestão Ambiental e Sustentabilidade, 5(9), 329-347, 2018. doi: 10.21438/rbgas.050922

Silva, A. C. da S.; Maccari, E. A.; Quoniam, L. M. Uma ferramenta para apoiar a seleção de dados no processo de descoberta de conhecimento em bancos de dados de produção acadêmica. Revista Gestão \& Tecnologia, 15(1), 298-318, 2015. doi: 10.20397/2177-6652/2015.v15i1.822
SIMA - Secretaria de Infraestrutura e Meio Ambiente do Estado de São Paulo. Plano de Manejo do Parque Estadual da Ilha do Cardoso. São Paulo, 2001. Disponível em: <https://www.infraestruturameioambiente.sp.gov.br/ fundacaoflorestal/planos-de-manejo/planos-de-manejo-planos-concluidos/plano-de-manejo-pe-ilha-do-cardoso/>. Acesso em: fev. 2019.

Souza, A. M.; Kurtz, D. J. Análise de modelos para a gestão do conhecimento organizacional: O caso serviço social da indústria - SESI/PE. International Journal of Knowledge Engineering Management, 3(6), 64-88, 2014. Disponível em: http://stat.ijkem.incubadora.ufsc.br/index.php/IJKEM/ article/view/2778

Valle, P. F. do. Conflitos e possibilidades da participação de comunidades locais na gestão do Parque Estadual da Ilha do Cardoso, São Paulo. São Paulo, Dissertação (Mestrado em Ciências) - USP, 2016.

Vieira, H. C.; Castro, A. E. de; Schuch Júnior, V. F. O uso de questionários via e-mail em pesquisas acadêmicas sob a ótica dos respondentes. In: XIII Seminários em Administração. São Paulo, 09 de set., 2010.

Vinuto, J. Amostragem em bola de neve na pesquisa qualitativa: um debate em aberto. Temáticas, 22(44), 203-220, 2014. doi: 10.20396/temáticas.v22i44.10977 